\title{
COMPETENNCIAS REQUERIDAS EM EQUIPES DE PROJETOS ÁGEIS: UM ESTUDO DE CASO EM UMA EDTECH
}

\author{
REQUIRED SKILLS IN AGILE PROJECT TEAMS: A CASE STUDY OF EDTECH
}

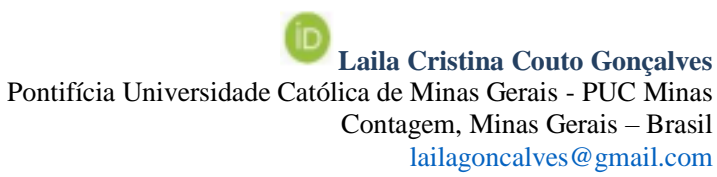

Silvia Alves Assumpção de Oliveira Pontifícia Universidade Católica de Minas Gerais - PUC Minas Belo Horizonte, Minas Gerais - Brasil silviaassumpcao28@gmail.com

Jéssica de Carvalho Amaral Pacheco Pontifícia Universidade Católica de Minas Gerais - PUC Minas Belo Horizonte, Minas Gerais - Brasi jessicapacheco2294@gmail.com

Paula Karina Salume Universidade Federal de São João del-Rei - UFSJ São João Del-Rei, Minas Gerais - Brasil paulasalume@ hotmail.com

\begin{abstract}
Resumo
Diferentes métodos de gerenciamento de projetos - abordagem tradicional e ágil - exigem características distintas da equipe, especialmente num contexto intensivo de tecnologia que requer alto desempenho. Neste sentido, o presente artigo busca identificar quais competências têm sido demandadas aos profissionais que atuam em projetos, no âmbito de abordagens ágeis, a fim de orientar gestores de projetos a formar equipes de alta performance, capazes de entregar valor, maior produtividade $\mathrm{e}$ lucratividade para as organizações. Para isso, foi realizado um estudo de caso em uma edtech, empresa startup educacional, através de entrevistas semiestruturadas, presenciais e virtuais, com colaboradores da empresa que compõem dois squads distintos. As entrevistas permitiram conhecer o perfil e as competências de cada profissional entrevistado, além de sua visão em relação ao ambiente de trabalho circunscrito em processos ágeis de gerenciamento de projetos e necessidade de equipes de alta performance. A pesquisa revelou que as principais competências valorizadas no time são: conhecimento técnico e da abordagem de projetos, comunicação, saber trabalhar em equipe, capacidade de execução, flexibilidade, liderança, colaboração e proatividade. Conclui-se que o time está no caminho de ser uma equipe de alta performance, porém ainda é necessário que os membros incorporem mais as práticas ágeis entendendo o real valor que as mesmas geram para os clientes, por meio do desenvolvimento dos seus produtos.
\end{abstract}

Palavras-chave: Projetos. Abordagem ágil. Equipes de alta performance. Competências.

\begin{abstract}
Different methods of project management - traditional and agile approach - require distinct team characteristics, especially in an intensive context of technology that requires high performance. The present article sought to identify which competencies have been demanded to the professionals who work in projects, in the context of agile approaches, in order to guide project managers to form high performance teams, capable of delivering value, greater productivity and profitability for organizations. For this, a case study was conducted at an edtech, educational startup company, through semi-structured interviews, presencial and virtual, with company employees that make up two different squads. The interviews allowed knowing the profile and the skills of each professional interviewed, as well as their vision regarding the work environment in agile project management processes and the need for high performance teams. The research revealed that the main skills valued in the team are: technical knowledge and project approach, communication skills, teamwork, ability to execute, flexibility, leadership, collaboration and proactivity. It is concluded that the team is on the way of being a high performance team, but it is still necessary that members incorporate more agile practices, understanding the real value they generate for customers, through the development of their products.
\end{abstract}

Keywords: Projects. Agile approach. High performance teams. Skills. 


\section{Cite como - American Psychological Association (APA)}

Gonçalves, L. C. C., Oliveira, S. A. A., Pacheco, J. C. A., \& Salume, P. K. (2020, set./dez.). Competências requeridas em equipes de projetos ágeis: um estudo de caso em uma Edtech. Revista de Gestão e Projetos (GeP), 11(3), 72-93. https://doi.org/10.5585/gep.v11i3.18476.

\section{Introdução}

O ambiente competitivo que emerge na era pós-industrial, caracterizado pela velocidade das mudanças tecnológicas e dos mercados instáveis, demanda habilidades de aprendizagem e flexibilidade para os resultados organizacionais (Carvalho \&Laurindo, 2003). Como consequência, o gerenciamento de projetos tornou-se um modelo de gestão estratégico essencial para as organizações, a fim de garantir sua sobrevivência e permanência no mercado.

Considera-se que as competências múltiplas e específicas da equipe de profissionais sejam fundamentais para que os modelos de gerenciamento de projetos alcancem os melhores resultados para suas organizações. Acredita-se que, para além de modelos inovadores e práticas consolidadas de gerenciamento de projetos, a alocação de recursos por competências e habilidades seja fundamental para potencializar a produtividade e o valor entregue pelas empresas.

$\mathrm{O}$ presente artigo buscou identificar quais competências têm sido demandadas aos profissionais que atuam em projetos, no âmbito de abordagens ágeis, com o intuito de orientar gestores de projetos a formar equipes de alta performance, capazes de entregar valor ao cliente sem desperdício e, consequentemente, gerar maior lucratividade para as organizações.
Além disso, propõe-se analisar as competências demandadas pelo mercado atual, nas dimensões do conhecimento, habilidades e atitudes (CHA), segundo o relatório do Fórum Econômico Mundial (Pati, 2016), baseando-se nas características de equipes de alta performance, especialmente as que utilizam métodos de gerenciamento ágeis, se organizam em squads, e adotam a técnica Kanban em sua rotina de condução de projetos.

Por abordagens ágeis de gerenciamento de projetos entende-se a nova onda de práticas de gerenciamento que se seguiu aos modelos tradicionais, como alternativa para um ambiente de negócios que se apresenta cada vez mais dinâmico, incerto e adaptativo, em que os projetos passam constantemente por mudanças de requisitos e que os resultados precisam ser entregues ao cliente em pequenos intervalos de tempo (Sutherland \&Schwaber, 2013). Dentre as abordagens ágeis, destaca-se o Scrum, que embora tenha sido desenvolvido visando sua aplicação no desenvolvimento de softwares, tem sido aplicado em todos os tipos de projetos que precisem ser mais versáteis e adaptáveis (Cruz, 2013).

As organizações que adotam o gerenciamento de projetos buscam potencializar a sua eficiência com o intuito de obter excelência e geração de resultados. A escolha das pessoas e suas respectivas 
competências podem ser o fator determinante que separa o sucesso do insucesso de um projeto. Por definição, competência é “a habilidade de um ator (indivíduo ou grupo) de agir e reagir com a relevância requerida para desempenhar um conjunto de atividades em situações diversas para determinado tipo de trabalho" (Sefiani, Boumane, Campagne, \&Bouami, 2012, p.265).

No contexto da abordagem ágil na gestão de projetos, há demanda por pessoas que realizem as mais diversas tarefas sem desperdício, que sejam capazes de gerir seus problemas, controlar seus resultados, propor soluções, visando garantir maior taxa de sucesso no alcance das metas e objetivos almejados (Mariano, 2008). Para isso, as organizações têm investido em desenvolver equipes de alto desempenho que sejam capazes de definir metas, tomar decisões, comunicarse, administrar conflitos em um ambiente de incentivo e confiança para atingir seus resultados (Dyer\&Dyer, 2011). Nesse intuito, essa pesquisa pretendeu identificar e confirmar essas competências de modo a estabelecer um caminho para a potencialização dos resultados organizacionais no contexto de mudança.

A pesquisa está estruturada em cinco seções, sendo a primeira essa introdução. A segunda seção traz o referencial teórico que serviu de base para a análise do caso de pesquisa, abordando as características do método e as diferentes competências profissionais requeridas em equipes de alta performance que trabalham com abordagens ágeis, métodos como Kanban e Squad, num contexto de transformação do mundo do trabalho intensivo em tecnologia. A terceira seção apresenta a metodologia de pesquisa utilizada, e na quarta seção é feita a apresentação da empresa e análise dos resultados. Por fim, a quinta seção contempla as considerações finais, limitações e as sugestões para estudos futuros.

\section{Referencial teórico}

De acordo com Almeida, Campagnac e Farias Filho (2008), o gerenciamento de projetos está inserido dentro das organizações como uma prática crescente e essencial, com inúmeros benefícios e de uma importância vital para os negócios. Um estudo realizado pela Harvard Business School (HBS) apontou que diversas têm sido as razões para a crescente adoção de práticas de gerenciamento de projetos. Dentre elas, ressaltam-se a importância do reconhecimento do gerenciamento de projetos como um fatorchave para o alcance dos objetivos estratégicos da organização, e para o aumento das pressões competitivas que demandam maiores níveis de eficiência e eficácia gerencial e organizacional, além de um olhar mais atencioso para o desenvolvimento de produtos (Harvard Business School [HBS], 1997).

As competências requeridas em equipes de projetos tendem a ser distintas conforme o método de gerenciamento que se adota, o tipo de atividade exercida pela empresa, a cultura organizacional estabelecida 
ou construída ao longo de suas atividades, o tipo de liderança que emerge em cada contexto e a gestão de mudanças organizacionais.

Entende-se que uma instituição pode moldar as competências de seus colaboradores ao estimular o desenvolvimento de perfis profissionais, seja pelo investimento em capacitação específica e mudança de paradigmas de dentro da empresa, seja pela necessidade de sobrevivência - aumento de produtividade, entregas com valor e qualidade. Fato é que as equipes podem ou não se adaptar aos métodos gerenciais, e se não corresponderem aos seus principais pressupostos, dificilmente entregarão os resultados almejados.

Para melhor compreender os parâmetros em que são analisadas as competências de uma equipe, é preciso observar alguns cenários em que cada grupo opera, a abordagem de projetos e as técnicas utilizadas. À medida em que se avança no processo de desenvolvimento e inovação tecnológica, como é o caso das Edtechs, percebe-se que as competências profissionais se deslocam fortemente à necessidade de equipes de alta performance, juntamente com a evolução dos métodos de gestão menos hierarquizados e mais autônomos.

\subsection{Abordagens ágeis}

Segundo Amaral, Conforto, Benassi e Araújo (2011), o gerenciamento de projetos por meio de métodos ágeis tem por objetivo tornar o processo de gestão mais simples, flexível e prático. Dessa forma, as abordagens ágeis vieram atender à necessidade de melhorar o desempenho dos projetos, com entregas mais rápidas, possibilidade de testes e inovações ao ter menor custo de gestão de mudanças, enxugar os processos e entrega de maior valor pelas empresas.

Sua origem se deu em fevereiro de 2001 em Utah (EUA), com a publicação do Manifesto Ágil após a reunião de um grupo de dezessete especialistas que discutiam abordagens para melhorar o desempenho de seus projetos de desenvolvimento de software (Balle, 2011). O documento contém um conjunto de conceitos e princípios, como (Highsmithet al.,2001):

a) Valorizar indivíduos e interações mais que processos e ferramentas;

b) Valorizar software em funcionamento mais que documentação abrangente;

c) Valorizar colaboração com o cliente mais que negociação de contratos;

d) Valorizar responder a mudanças mais que seguir um plano.

Dentre os vários tipos de abordagens ágeis existentes, o que mais se destaca é o Scrum, um framework iterativo e incremental, concebido por Jeff Sutherland e Ken Schwaber (Carvalho \&Mello, 2009). É conhecido por ser um framework objetivo e ágil que auxilia no gerenciamento de projetos complexos e no desenvolvimento de produtos (Prikladnicki,Willi, \& Milani, 2014). 
O Scrum implementa um esqueleto iterativo e incremental por meio de três papéis principais (Schwaber, 2014): a)Product Owner (PO), ou dono do produto, que representa os interesses de todos no projeto e é a pessoa que define todos os itens de requerimento do projeto; b)Scrum Time, que é a equipe que desenvolve as funcionalidades do produto; e c)Scrum Master, o qual garante que todos sigam as regras e práticas do Scrum, além de ser o responsável por remover os impedimentos do projeto.

No Scrum, um projeto inicia-se com uma visão simples do produto que será desenvolvido. O Product Owner transforma essa visão em uma lista de funcionalidades a ser implementada. Essa lista, chamada Product Backlog, é priorizada pelo PO, de modo que os itens que geram mais valor ao produto tenham prioridade. O processo de desenvolvimento é dividido em intervalos de tempos que podem variar de duas a quatro semanas, chamados de Sprints. As atividades realizadas dentro de um Sprint são definidas em uma reunião chamada Sprint Planning Meeting, em que as atividades a serem desenvolvidas são transferidas para o Sprint Backlog, ajustados de acordo com as prioridades de cada projeto em questão e a capacidade do Scrum Team em entregar a atividade durante a Sprint que se inicia (Prikladnicki, Willi, \& Milani, 2014).

A cada dia de Sprint é realizada uma reunião rápida com toda a equipe, chamada de dailyscrum meeting, visando à identificação e correção de quaisquer deficiências e/ou impedimentos no processo de desenvolvimento (Schwaber, 2014). Ao final de um Sprint, a equipe apresenta as funcionalidades implementadas em uma reunião denominada Sprint Review Meeting. Por fim, faz-se uma última reunião, a Sprint Retrospective, com o intuito de revisar as práticas do Scrum e refletir sobre o que precisa melhorar antes que a equipe inicie o planejamento da próxima Sprint (Prikladnicki, Willi, \& Milani, 2014).

\subsection{Kanban}

O método Kanban introduzido na Toyota é uma ferramenta de gestão visual que busca, primordialmente, a visualização e a otimização do trabalho em equipe de modo a melhorar o desempenho, reduzir o desperdício e eliminar as atividades que não agregam valor para a equipe (Boerg, 2018).

Trata-se da instituição de um quadro ou mural (físico ou virtual), estrategicamente posicionado (fácil visualização), dividido em colunas com cartões, post-its ou sinalizadores, que identificam o status das atividades do projeto, geralmente divididos em "A fazer", "Em andamento" e "Concluídos", aos quais pode também ser incluída a coluna "Aguardando", que identifica ainda mais facilmente os bloqueadores e dependências das atividades para que sejam, assim, imediatamente identificados e resolvidos. Cada cartão deve possuir informações sobre item de trabalho, responsável pelo item, descrição da tarefa e estimativa de tempo para sua conclusão. 
O Kanban propõe assegurar a rastreabilidade das tarefas e facilidade na colaboração entre os membros - por requerer menor organização -, além da redução de desperdícios, redução de custo, processos simplificados, menos burocracia na atribuição de tarefas (sem a necessidade de documentos, memorandos ou ofícios para isso) maior visibilidade dos projetos, eliminação de atividades que não agregam valor, redução de tempo ocioso entre os colaboradores, melhoria na motivação e desempenho da equipe, entre outros (Prikladnicki, Willi, \& Milani, 2014).

$\mathrm{O}$ método Kanban permite que uma equipe acostumada a trabalhar com abordagens ágeis de gerenciamento de projetos, especialmente o Scrum, possa se beneficiar enormemente ao aliar essa técnica à sua rotina de trabalho, pois reflete as Sprints com eficácia, sendo esses métodos de gerenciamento complementares. Nesse contexto, os quadros Kanban tornam-se importantes instrumentos de monitoramento e controle, conduzindo ao alcance das metas de desempenho acordadas.

Segundo Boerg (2018), métodos e processos de trabalho inovadores acompanham projetos também inovadores. Dessa maneira, as equipes se adaptam e remanejam para melhor atenderem às demandas dos projetos. Assim, novos conceitos de equipe têm surgido no contexto do gerenciamento de projetos, como é o caso do squad.

\subsection{Squad}

Num contexto de projetos inovadores, as empresas têm implementado, também, processos novos de gestão de pessoas, composição de equipes e atribuições de papéis e responsabilidades entre os colaboradores. Um deles é o squad, também chamado de "esquadrões", conceituado como um time cross-funcional com autonomia na definição de prioridades dentro do projeto, sem que se perca o alinhamento à estratégia e aos objetivos da empresa.

Pode-se dizer que o squad é projetado para dar maior velocidade de desenvolvimento dos produtos e prestação de serviços da empresa, uma vez que contribui para reduzir o desperdício e minimizar o tempo de inatividade da equipe. Caracteriza-se por grupos de 3 a 10 membros com características complementares capazes de desenvolver o projeto em sua completude. São modelos mais adaptativos, isto é, possuem maior capacidade de realinhamento de rotas para atender às demandas de projetos. Exige, por isso, alto grau de alinhamento e autonomia da equipe (Rebelo, 2013).

Os times cross-funcionais são cada vez mais desejados em organizações com equipes de alta performance, uma vez que a comunicação se torna mais eficiente e constante, o que promove melhoria do clima organizacional e aumento de produtividade (Rotta, Rados, Trierweiller, \& Silva, 2015). A ausência de visão departamental garante, também, agilidade nos processos, maior 
integração e velocidade no processo de tomada de decisão.

Rebelo (2013) ressalta que aspectos devem ser observados para que squads funcionem bem dentro da empresa. O primeiro é garantir o alinhamento estratégico dos membros do time, de modo que sejam assertivos no processo autônomo de definição de prioridades. O segundo é a avaliação do impacto da implantação de times crossfuncionais em organizações ainda muito tradicionais e hierarquizadas; é importante que essa inovação não entre em conflito com a cultura da empresa, podendo encontrar resistências pelos demais colaboradores. $\mathrm{O}$ terceiro é a necessidade de se enfrentar, lidar e resolver problemas por parte do time, o que exige responsabilidade, preparo e ciência em relação aos seus próprios hábitos. O quarto, mas que não exaure o tema, é o real envolvimento dos membros com o propósito, os valores e objetivos da empresa, e não apenas com suas entregas particulares - é o que diferencia um grupo (pessoas com funções estabelecidas e atividades individuais) de um time (cujo resultado advém do trabalho coletivo) (Sabbagh, 2013).

\subsection{Edtech}

As novas abordagens de trabalho em equipe emergem em resposta a setores inovadores em seus produtos e processos, especialmente voltados à tecnologia (ou que se fazem uso intensivo dela), chamados de startups. Startups são empresas enxutas e experimentais, que lançam produtos tecnológicos que procuram resolver um problema comum e amplo, com rápida capacidade de entrega com valor para a sociedade (ou seu público-alvo) e alto grau de adaptabilidade às mudanças de mercado (Camara, 2018).

Dentre os setores mais relevantes de startups está o mercado educacional, que desponta no Brasil e no mundo com valor cada vez mais crescente, tanto pelo tamanho do desafio de capacitar pessoas, quanto pelo potencial que a educação possui de transformar a sociedade de maneira significativa (Camara, 2018). Esse tipo de startup é conhecido como Edtech, pois aliam a tecnologia aos métodos pedagógicos para trazer inovação e potencializar o aprendizado. As Edtechs revelam a grande necessidade de se atualizar os métodos tradicionais de ensino tão institucionalizados nos dias de hoje, mesmo num contexto de revolução digital em que se vive, ainda mais as crianças e jovens que já nasceram nessa realidade

Conforme pontua Camara (2018), esse tipo de empresa apresenta algumas características específicas. Primeiramente, lida com a inovação de inserir mais um ator no processo de aprendizado: a tecnologia. No equilíbrio desta com os alunos e professores, descobre-se que é necessário empreender mais esforços em integrar o professor do que o aluno à tecnologia. Em segundo lugar, beneficia-se da formação de base de dados inicial que tende a dobrar, triplicar, se 
multiplicar ao longo dos anos. Ao conteúdo específico passa, portanto, a trabalhar com o gerenciamento de informações, o que pode render subprodutos ou auferir ganhos primariamente não mapeados. Além disso, promove a melhoria do ensino das pessoas, o que por si só já traz grande motivação devido à sua capacidade de contribuir para a alteração de uma realidade social. Ademais, traz benefícios financeiros aos empreendedores (é um setor lucrativo) ao mesmo tempo que trabalha com propósitos, entregando valor para a sociedade, combinação ideal e desejada no mundo corporativo. Por fim, é o setor que incorpora as principais inovações no setor educacional nos dias atuais, e que ainda possui muito campo para ser desvendado, investido e empreendido. As edtechssão empresas que possuem muita oportunidade de crescimento e, certamente, bastante capacidade de testar e inovar produtos, serviços e processos.

\subsection{O tripé da competência e equipes de alta performance}

Nas organizações, competência inclui habilidades técnicas e comportamentais presentes nos membros de uma equipe que contribuem para o alcance dos objetivos das organizações. Portanto, capacidades técnicas não são suficientes para definir competências, uma vez que devem ser complementadas com as capacidades comportamentais (Parry, 1996).

O conceito de competência para Le Boterf (1995) é determinado pela combinação de conhecimentos, habilidades e atitudes relevantes e desejadas a uma função. É saber agir tendo responsabilidade, conseguir transferir seus conhecimentos e sendo reconhecido pelos outros pelo seu trabalho. Barato (1998) acrescenta que competência deve ser compreendida como sendo a base principal no desenvolvimento das organizações, e deve ser desenvolvida através da interação entre as pessoas dentro do ambiente de trabalho.

Leme (2005) menciona que a competência é constituída de três pilares, conhecido na comunidade acadêmica pelo acrônimo CHA. Rabaglio (2001) define significados para esses pilares, assim como segue:a) Conhecimento: base adquirida no decorrer da vida por meio de diferentes recursos seja pelo estudo formal, treinamento, leitura, ou até mesmo a simples observação; b)Habilidade: capacidade de realizar determinada tarefa, física ou mental a partir do conhecimento adquirido. Geralmente é desenvolvida pela prática, tempo e experiência de execução; c) Atitude: comportamentos diante de situações do cotidiano e das tarefas desenvolvidas no dia-a-dia.

Assim, Prahalad e Hamel (1990) e Durand (1998) afirmam que gestão por competência consiste em dar suporte a gestão de pessoas visando desenvolver competências consideradas essenciais para a obtenção dos objetivos organizacionais. Dessa forma, Betti (2011) afirma que as equipes que estão alinhadas e caminham por um objetivo comum e que possuem um elevado grau de 
comprometimento são definidas como equipe de alta performance.

O Fórum Econômico Mundial (Pati, 2016) exemplifica em seu relatório as dez competências que serão exigidas no mercado em 2020, quais sejam:

a) Resolução de problemas complexos: ter capacidade para resolver problemas definidos como complexos;

b) Pensamento crítico: usar da lógica e da racionalização para identificar forças e fraquezas de soluções alternativas;

c) Criatividade: capacidade de avançar com ideias inteligentes sobre uma determinada situação, ou para desenvolver formas criativas de resolver um problema;

d) Gestão de pessoas: capacidade de motivar, desenvolver pessoas e de identificar talentos;

e) Coordenação: coordenar as próprias ações de acordo com as ações de outras pessoas, para facilitar alguns processos;

f) Inteligência emocional: estar ciente das reações dos outros e entender por que eles reagem dessa forma e como lidar com isso;

g) Capacidade de julgamentos e de tomada de decisões: saber analisar dados e o ambiente para tomar decisões assertivas a partir disso;

h) Orientação de serviço: buscar maneiras de orientar as pessoas;

i) Negociação: saber relacionar com as pessoas e tentar reconciliar as diferenças; j) Flexibilidade cognitiva: capacidade de criar ou usar diferentes conjuntos de regras para combinar ou agrupar as coisas de diferentes maneiras.

O Fórum Econômico Mundial (Pati, 2016) reuniu as principais características de equipes de alta performance que são determinadas por talentos e competências que se complementam, propósitos em comum, união e foco em objetivos, altíssimo grau de comprometimento, resultado de alto nível, colaboração e esforços na resolução dos problemas e, consequentemente, um constante resultado de qualidade. Geralmente não são equipes tão grandes, uma vez que equipes mais enxutas provaram ser mais produtivas, colaborativas, com baixo custo de comunicação e melhor gerenciadas.

Equipes com essas características vêm responder aos métodos mais modernos de gerenciamento de projetos em contextos intensivos de tecnologia, mudanças rápidas e constantes, no qual exigem grande resiliência e adaptabilidade de seus colaboradores. Dados os parâmetros que foram apresentados, a pesquisa avança na investigação das competências encontradas entre profissionais que atuam em projetos de abordagens ágeis numa edtech.

\section{Metodologia}

Para a realização da presente pesquisa optou-se por uma abordagem qualitativa, por meio de um estudo de caso único, justificada por seu caráter aberto focando particularmente 
no contexto de uma realidade (Godoy, 1995). Bryman (1989) salienta que esse tipo de investigação requer uma coleta de dados que se dá por meio de observação direta, entrevistas, documentos e registros em arquivos.

A primeira etapa da pesquisa consistiu em buscar respaldo teórico com o intuito de delimitar o que seria investigado, de modo a proporcionar fundamentos para o estudo e obter um aprofundamento sobre o tema (Miguel, 2007). Deste modo, o estudo contemplou uma pesquisa sobre os seguintes assuntos: abordagem ágil de projetos, edtech, squad, competências e sua relação com equipes de alta performance.

Para atender ao objetivo de pesquisa, buscou-se uma organização que atendesse aos seguintes critérios: a) adotar abordagem de gerenciamento de projeto ágil; b) acesso aos profissionais e disponibilidade de informações. De acordo com os parâmetros, o estudo foi realizado em uma edtech, empresa de ambiente inovador e colaborativo que desenvolve soluções educacionais tecnológicas para $\mathrm{o}$ ensino básico e superior.

Para conhecer as características da equipe, coletou-se dados primários por meio de entrevista em profundidade, orientada por um instrumento de coleta de dados semiestruturado. As entrevistas foram realizadas de forma presencial e virtual com 12 (doze) colaboradores da empresa. O objetivo foi conhecer o perfil do profissional entrevistado, suas competências, sua visão em relação ao ambiente e a forma de trabalho em que está inserido.

O estudo analisou dois squads da mesma empresa. No squad A, responsável pelo desenvolvimento de produtos para o Ensino $\begin{array}{lll}\text { Superior entrevistou-se } 9 & \text { (nove) }\end{array}$ colaboradores, sendo: A1: Product Manager; A2: Product Owner; A3: Scrum Master; A4: Analista de dados; A5: UX/UI Designer; A6: Estagiária de produto; A7: Líder Técnico de TI; A8: Desenvolvedor e A9: QA (Quality Assurance). Já no squad B, responsável pelo desenvolvimento de produtos para o Ensino Básico foram 3 (três) entrevistados: B1: Product Owner; B2: UX/UI Designer e B3: Estagiário de desenvolvimento.

Como última etapa, realizou-se a análise dos dados por meio da técnica de análise de conteúdo, que visa uma descrição e interpretação das informações de toda a classe de documentos e textos de maneira objetiva e sistemática (Olabuenaga \& Ispizúa, 1989). Bardin (2011) indica que a utilização da análise de conteúdo prevê três momentos fundamentais, sendo estas: pró-análise, exploração do material, tratamento dos resultados: a inferência e a interpretação.

$\mathrm{Na}$ fase de pré-análise ocorreu a transcrição dos áudios obtidos nas entrevistas para facilitar o trabalho de compreensão e interpretação. $\mathrm{Na}$ fase de exploração do material, utilizou-se a análise categorial, que consiste na subdivisão e agrupamento do texto em categorias segmentadas (Bardin, 2011). A escolha pela análise categorial é justificada por 
ser a melhor alternativa quando se deseja estudar atitudes, opiniões, valores e crenças, por meio de dados qualitativos. Para responder ao objeto de pesquisa, a categorização dos dados se deu em função do CHA, por abranger todas as dimensões que caracterizam o conceito de competência. Rabaglio (2001) contribui afirmando que cada indivíduo possui suas competências associadas às características individuais representadas pelo conhecimento, habilidade e atitude que impactam em seu desempenho nos resultados atingidos.

Por fim, realizou-se a análise reflexiva e crítica dos resultados, apresentando as competências relatadas pelos entrevistados, e comparando estas as competências demandadas ao profissional do futuro segundo o relatório do Fórum Econômico Mundial (Pati, 2016), a fim de identificar quais competências têm sido requeridas para formar equipes de alta performance nos times de projetos ágeis.

\section{Apresentação e análise dos resultados}

\subsection{Descrição do caso}

A empresa em estudo, fundada em 2012, em Belo Horizonte, nasceu como um startup no setor educacional, com a missão de gerar mais oportunidades para as pessoas e com o objetivo de democratizar a educação de qualidade. Em 2017, a startup foi adquirida pela maior empresa de educação básica do Brasil, ampliando seu mercado de atuação.

Os sócios desenvolveram um modelo de negócio baseado, inicialmente, em um aplicativo para que os alunos pudessem testar seus conhecimentos por meio de quizzes especialmente preparados com conteúdo educacionais, viabilizando a preparação para o Exame Nacional do Ensino Médio (ENEM). Atualmente, o portfólio também auxilia estudantes de ensino fundamental e candidatos a exames padronizados, como aquele da Ordem dos Advogados do Brasil (OAB).

Sob a ótica de uma estrutura organizacional funcional são dispostos, aproximadamente, 168 colaboradores para desenvolver soluções para a educação básica e o ensino superior. Nestas frentes, a organização do trabalho se dá por meio de squads compostos por profissionais multidisciplinares, que têm como foco a resolução de um problema específico.

\subsection{As competências requeridas em profissionais de projetos}

Com base nos dados coletados, identificou-se as competências dos profissionais em projetos ágeis, as quais foram relacionadas às dimensões do CHA: Conhecimento, Habilidade e Atitude, conforme mostra a Figura 1. 
Figura 1- Categorização das competências

\begin{tabular}{|l|l|}
\hline \multicolumn{1}{|c|}{ CHA } & \multicolumn{1}{c|}{ Principais pontos abordados } \\
\hline \multirow{4}{*}{ Conhecimento } & Conhecimento técnico \\
\cline { 2 - 3 } & Conhecimento da abordagem de projetos \\
\cline { 2 - 3 } Habilidade & Conhecimento das ferramentas de acompanhamento e comunicação \\
\hline & Comunicação \\
\cline { 2 - 3 } & Saber ouvir \\
\cline { 2 - 3 } Atitude & Flexibilidade \\
\cline { 2 - 3 } & Saber trabalhar em equipe \\
\cline { 2 - 3 } & Liderança \\
\cline { 2 - 2 } & Capacidade de execução \\
\hline & Aderir às cerimônias do scrum \\
\cline { 2 - 2 } & Colaboração \\
\cline { 2 - 2 } & Adaptabilidade \\
\cline { 2 - 2 } & Proatividade \\
\hline
\end{tabular}

Fonte: Elaborado pelos autores.

\section{A dimensão Conhecimento é composta}

pelas categorias conhecimento técnico, conhecimento da abordagem de projetos e conhecimento das ferramentas de acompanhamento e comunicação. Já a dimensão Habilidade compreende as categorias comunicação, saber ouvir, flexibilidade, saber trabalhar em equipe, liderança e capacidade de execução. Por fim, a dimensão Atitude engloba as categorias aderir às cerimônias do scrum, colaboração, adaptabilidade e proatividade.

Os resultados obtidos pelas entrevistas realizadas com os colaboradores da edtech são apresentados para cada dimensão de competência.

\subsubsection{Conhecimento}

A primeira categoria, "conhecimento técnico", identificou a formação dos entrevistados no que diz respeito a cursos, certificações, workshops, graduação, especialização, pós-graduação, MBA e/ou mestrado. Considerando a formação acadêmica, observou-se que a maioria dos respondentes possuem um grau de instrução elevado, maiormente com nível superior completo, seguido de pós-graduação e mestrado. Notou-se que alguns entrevistados possuem certificações nas mais diversas áreas de especialização, além da formação acadêmica de nível superior.

Borges (2017) afirma que as especializações profissionais têm como 
objetivo aprofundar estrategicamente os conhecimentos em determinada área, nas quais são desenvolvidas habilidades para minimizar conflitos, encontrar soluções variadas, gerar oportunidades e inovar. No entanto, apenas uma pequena parte dos entrevistados apresenta curso ou certificação na área de projetos.

No que tange a segunda dimensão, o "conhecimento da abordagem de projetos", observa-se a disseminação da cultura ágil nos quad A, feito sob a orientação do scrum master. Este, contudo, relata que é uma tarefa trabalhosa, pois alguns desenvolvedores possuem resistência a seguir processos, especialmente os novos. O respondente A3 relata ainda que sempre tenta mostrar para a equipe o valor de seguir a abordagem ágil. Essa atitude do entrevistado vai ao encontro do que defende Chiavenato (2004), que afirma que ações para disseminar o conhecimento da metodologia utilizada é um meio de desenvolver competências nas pessoas para que elas se tornem mais produtivas, de modo a contribuir para o alcance dos objetivos organizacionais.

No que diz respeito ao "conhecimento das ferramentas de acompanhamento e comunicação", todos os respondentes relatam conhecer e utilizar o slack, como principal ferramenta de comunicação, um aplicativo de comunicação que oferece uma plataforma na qual equipes podem se comunicar rapidamente com mensagens de texto e voz, além de permitir o envio de vídeos e documentos, mantendo tudo organizado e centralizado. Se tratando de acompanhamento do projeto, a ferramenta Jira, um software que permite o monitoramento de tarefas e acompanhamento de projetos garantindo o gerenciamento de todas as suas atividades em um único lugar. $\mathrm{O}$ respondente A2 ressalta a importância dessas ferramentas, afirmando que o slack é fundamental para ter uma comunicação mais rápida e eficaz e o Jira para ter uma visão do projeto e ver como a equipe está caminhando e quais são os próximos passos. Prado (2009) afirma que o uso de ferramentas de gestão de projetos torna-se indispensável para garantir resultados positivos no desenvolvimento de um projeto, pois permite saber quais métodos e processos de trabalho e visualizar o desenvolvimento da equipe.

\subsubsection{Habilidade}

A segunda dimensão possibilita analisar a capacidade do indivíduo em aplicar o conhecimento que detém. Esta dimensão foi dividida em seis categorias: comunicação, flexibilidade, saber trabalhar em equipe, saber ouvir, liderança e capacidade de execução.

A comunicação eficaz foi mencionada pelos entrevistados como uma das habilidades mais importantes, visto que cria uma ponte entre as diversas partes interessadas, influência na interação do time e no adequado andamento e sucesso dos projetos. Segundo uma pesquisa realizada pelo Project Management Institute Brasil (PMI®), 76\% de 300 grandes empresas definem a comunicação no ambiente de trabalho como o principal motivo de fracasso 
no desenvolvimento de atividades. Dentro dessa categoria, analisou-se a comunicação entre os integrantes do time de projetos, a comunicação com os times remotos e a prática de feedback.

A comunicação informal e direta (face a face) foi dita pelos entrevistados como a mais utilizada no cotidiano, dado o alto grau de interação da empresa. O PMBOK® (Project Management Institute, 2017) ressalta que dentre estas formas de comunicação estão $e$ mail, mídias sociais, discussões informais e outros. Os respondentes acrescentam a isso a utilização de outras formas, tais como: slack, whatsapp, discord, hangout e Skype para a troca de informações com os times remotos, dada a necessidade de agilidade e de registro das informações trocadas. Para Lima (2012), a comunicação informal é mais valorizada do que a comunicação formal no ambiente de desenvolvimento ágil, porém isso não significa que a formalidade não exista.

Em relação à comunicação com os times remotos, os entrevistados relatam que o principal desafio é manter uma comunicação eficiente, visto que é normalmente considerada muito mais complexa para quem trabalha remotamente do que para pessoas trabalhando no mesmo ambiente. De fato, a comunicação com times remotos requer maior comprometimento das partes envolvidas em repassar as informações, manter os membros atualizados e envolvidos. Paradela e Peeters (2001) enfatiza esse aspecto ao afirmar que uma das principais desvantagens evidenciada quando se fala em trabalho remoto é a diminuição de laços sociais e o aumento de complexidade na comunicação.

A cultura de feedback é outra prática de comunicação muito estimulada e praticada dentro da empresa pesquisada. Segundo Jurane Godfrey (1998), as ideias e feedback dos colaboradores são essenciais, e estes só são possíveis quando as pessoas sentem que podem expor suas opiniões sem censura ou repressão da gestão. A realização de feedbacks na referida empresa adota dois métodos, que são a one-o-one e o pulso. A one-o-one é a reunião de feedback individual, na qual o líder se reúne semanalmente ou quinzenalmente com o liderado para acompanhar o desenvolvimento, a satisfação e as suas expectativas quanto ao projeto. $\mathrm{O}$ pulso, por sua vez, é uma ferramenta formal de feedback da empresa em que o indivíduo se auto avalia e analisa o desempenho do seu líder. Essa ferramenta é preenchida uma vez, no final do ano, por todos os colaboradores. Posteriormente, em uma reunião de feedback, cada líder se reúne com seu liderado para discutir os resultados do pulso, analisar os pontos fortes e fracos e o que pode ser melhorado.

Em se tratando de um ambiente inovador e colaborativo, o "saber ouvir" foi outra habilidade dita como essencial para o profissional em um ambiente ágil. Ao receber uma informação, é preciso antes de tudo processá-la e entendê-la, para que a reação seja menos intempestiva e emotiva, e mais 
profissional e objetiva na resolução do problema ou questão comunicada (Cruz, 2014). Alguns dos respondentes revelam que há momentos no qual falta paciência e compreensão de algumas pessoas em ouvir o que o outro deseja transmitir, o que provoca desconforto em quem deseja se expressar e consequentemente conflitos negativos no time.

As transformações nas relações de trabalho e as mudanças do mercado exigem cada vez mais habilidades além das eminentemente técnicas. Verificou-se que a "flexibilidade" é uma habilidade indispensável no qual o profissional precisa ter capacidade de rápida adaptação às mudanças. $\mathrm{O}$ respondente A2 explica que no contexto do squad A, diversas vezes o time precisou readaptar-se para responder às mudanças de requisitos do projeto e garantir entrega de valor ao cliente. No que se refere à flexibilidade ao modo de trabalho, os entrevistados apontam como positivo o fato de poderem trabalhar um dia da semana remotamente, não terem um horário de trabalho rígido e autonomia para definir o ritmo das próprias tarefas, embora tenham consciência que precisam se adequar para realizar as entregas no prazo. Segundo Martin (1997), essa forma de flexibilidade leva o indivíduo a ter "maior responsabilidade por tomadas de decisões imediatas e uma participação mais ativa".

A habilidade "saber trabalhar em equipe" diz respeito à contribuição do indivíduo para o desempenho do time em determinadas ações visando um objetivo em comum. Um dos componentes do trabalho em equipe é assumir as atividades designadas com compromisso, gerando confiança com os integrantes da equipe (López-Bao, Palomares, Rodríguez, \& Ferreras, 2011). Segundo os entrevistados, o trabalho em equipe promove sinergia entre as pessoas, compartilhamento de informações, melhoria na comunicação e contribui para a solução de conflitos. Robbins (2005), Corrobora com a visão ao afirmar que o trabalho em equipe permite uma maior interação dos indivíduos, uma comunicação mais eficiente o que possibilita melhores resultados para a organização.

De acordo com Yukl (2013), é possível analisar a "liderança" por meio de uma perspectiva tridimensional, relacionando os aspectos de execução da tarefa, desenvolvimento de pessoas e estratégia.

De forma geral, os respondentes ao serem questionados sobre o que é liderança, mencionaram ser uma atividade que determinadas pessoas que assumem o papel de líder exercem com o intuito de influenciar e motivar indivíduos para convergir esforços em prol de um objetivo do time ou da organização, além de promover um bom ambiente de trabalho. O pensador George R. Terry, nos anos 1960 corrobora essa ideia ao afirmar que "Liderança é a atividade de influenciar pessoas fazendo-as empenhar-se voluntariamente em objetivos de grupo".

Tanto o Product Manager quanto o líder técnico, lideranças do squad A, ressaltam que o líder deve centrar-se na eliminação de 
obstáculos, prover um bom ambiente de trabalho e garantir que o time tenha tudo o que precisa para executar suas tarefas. Além disso, reafirmam a função do líder de disseminar os objetivos e metas da organização, além de prover todo o feedback necessário para que as pessoas possam se desenvolver como profissionais e, até mesmo, como pessoas. Motta (2004) afirma que essa interação dos indivíduos é um instrumento de harmonização interna da organização para que se alcance os objetivos comuns de maneira mais eficiente e eficaz.

$\mathrm{Na}$ visão dos liderados de ambos os squads é positiva a forma como os líderes conduzem os times. De maneira geral, acreditam que esses devem ter um olhar sistemático, incluindo uma perspectiva cautelosa sobre os recursos, processos e as metas, além de manter a equipe focada no projeto e em sua entrega de valor para o cliente. A maioria dos entrevistados apontam o feedback e a autonomia a eles conferida como quesitos mais importantes em relação ao modelo de gestão dos líderes. Sobre os feedbacks relatam que contribui para o reconhecimento do trabalho, diminuição de incertezas no projeto, processo de aprendizagem e melhoria contínua.

Por fim, "capacidade de execução" que caracteriza a habilidade do indivíduo em realizar algo efetivamente. Magill (2000) afirma que capacidade de execução está relacionada ao desempenho do indivíduo numa diversidade de habilidades ou de tarefas.
Refere-se a potencialidade individual para execução de atividades, que podem ser desenvolvidas por meio de treinamentos. Para o respondente $\mathrm{A} 2$, capacidade de execução é sinônimo de comprometimento e entrega de qualidade. $\mathrm{O}$ entrevistado relata que esse comprometimento dos colaboradores em executar suas atividades de forma efetiva corrobora para que as entregas do projeto ocorram dentro do prazo e com a qualidade esperada pelo cliente.

\subsubsection{Atitude}

A terceira dimensão possibilita analisar o modo de agir e reagir no dia a dia em relação aos fatos e outras pessoas em seu ambiente. Esta dimensão foi dividida em quatro categorias.

A primeira categoria da dimensão atitude tem por objetivo verificar o nível de “aderência às cerimônias do Scrum”. Esse processo ágil propõe rituais que acontecem dentro de um ciclo de desenvolvimento do projeto. Conforme Prikladnicki, Willi e Milani. (2014), existem 4 cerimônias: Sprint Planning, Daily Scrum, Sprint Review e Sprint Retrospective.

De forma ampla, os entrevistados conhecem as cerimônias e entendem que a utilização correta aumenta as chances de sucesso para entrega do projeto. A respondente A1, salienta que um dos benefícios dessas cerimônias é promover a integração do time de modo que trabalhem em prol de um objetivo comum e bem alinhado. No entanto, alguns 
entrevistados relatam que possuem dificuldades de praticar alguns rituais conforme manda o scrum devido ao conhecimento sobre os processos serem superficiais.

Os entrevistados de ambos os squads relataram que na organização são realizadas todas as cerimônias. Os resultados das entrevistas demonstraram que a cerimônia de sprint planning é a mais conhecida e que possui mais aderência do time, visto que a maioria apresenta um conhecimento do seu funcionamento e um propósito bem alinhado. As outras cerimônias também foram mencionadas, porém com um grau de relevância menor que a sprint planning. Notou-se que a sprint review é a que possui menor aderência, podendo ser explicado pela hipótese de perda de tempo em revisar ou apresentar o projeto, visto que passará por um processo de análise de qualidade.

A "colaboração" no ambiente de trabalho foi citada pelos entrevistados como fator essencial para o trabalho em equipe em prol de melhores resultados para organização. Observa-se que o conceito de colaboração é atribuído pelos respondentes como um auxílio entre os indivíduos em relação a processos, conhecimento técnicos ou do negócio. Nenhum respondente atribui o colaborativismo como algo negativo, e sim o oposto, ao declararem que a adoção deste comportamento contribui para a potencialização dos resultados do projeto, da organização e do indivíduo.
A categoria "adaptabilidade" foi mencionada pelos entrevistados como uma atitude necessária frente às situações do dia a dia e o ambiente de trabalho ágil no qual estão inseridos. Marques (2016) ressalta que adaptabilidade, é capacidade que um indivíduo tem de se adaptar de acordo com as necessidades, situações e circunstâncias. Tratase da aptidão de viver em condições diferentes daqueles aos quais está naturalmente acostumado. Dentro dessa categoria analisouse a necessidade de adaptação frente a mudança de função, mudança estrutural do time e mudanças impostas pelo ambiente ágil.

$\mathrm{O}$ quesito mudança de função foi tratado pelos entrevistados como um processo desafiador, uma vez que, o tempo de adaptação e incorporação às mudanças é curto devido a agilidade e dinamismo do mercado. Ressaltaram ainda que a aprendizagem necessária para o desempenho da nova função atribuída ocorre por meio da observação, conversas informais ou formais em reuniões e encontros, consulta a fontes de informações diversas, facilitada por um contexto de colaborativismo e complementaridade, independentemente do nível hierárquico que ocupam. A importância da interação entre pessoas e da cooperação em um cenário de mudanças é reforçada por Nonaka e Takeuchi (1997) ao afirmarem que o conhecimento pessoal de um indivíduo deve ser compartilhado com os outros, pois é por meio dessa interação que o conhecimento tácito pode ser transformado em explícito. 
Além deste aspecto, os entrevistados apresentaram opiniões comuns acerca do quesito de mudança estrutural dos times. Tratam esse processo como uma readaptação das formas de trabalho na qual acreditam que otimiza a gestão dos projetos e possibilita mais autonomia nas decisões, além de promover maior integração do time. Para os respondentes do squad A, essa nova estrutura ainda se encontra em formação, visto que precisam de um número de pessoas hábil para essa nova configuração. Diferentemente do squad B, que já tem a organização do projeto sob a forma de vários squads.

Quanto a "proatividade" no ambiente de trabalho, todos os respondentes em notoriedade relataram que esse comportamento quando desenvolvido pode resultar em impactos positivos no desempenho do indivíduo e assim em melhores resultados para organização. Gava (2009) válida a perspectiva dos respondentes ao afirmar que o comportamento proativo influencia positivamente a performance empresarial, tendo como consequência resultados superiores àqueles comportamentos que somente respondem relativamente ao mercado.

Notou-se que o aspecto de participação nas atividades-extra disseminadas na empresa possui alto grau de relevância pelos entrevistados ao enxergarem essa atitude como um comportamento proativo. Observa-se que os respondentes possuem uma alta aderência à Cumbuca, sobre esta atividade explicam que é uma ação em que as pessoas realizam uma leitura especializada de livros da área $\mathrm{e}$ posteriormente em encontros semanais explanam sobre a leitura. Outra atividade é o Comitê Gente e Gestão, o qual é composto voluntariamente pelos membros da empresa e que visa uma melhoria contínua do ambiente, através de ações de integração e bem-estar entre os colaboradores no ambiente de trabalho. Os entrevistados enfatizaram que essas ações promovem colaboração e comunicação entre as diferentes áreas da empresa.

\section{Considerações finais}

O desempenho das organizações, inseridas no atual processo de transformação digital, competitividade crescente e dinamismo, é melhor compreendido sob a ótica da gestão por competências associada às abordagens de gerenciamento de projetos. Assim, o presente artigo pretendeu identificar e confirmar competências requeridas em equipes de projetos ágeis, a partir das dimensões conhecimento, habilidade e atitude (CHA), de modo a estabelecer um caminho para a potencialização dos resultados organizacionais no contexto de mudança.

Por conhecimento entende-se o domínio conceitual dos colaboradores sobre as atividades ligadas a sua função e seu cotidiano, corroborando com o conceito de conhecimento encontrado na literatura. As entrevistas revelaram uma visão mais cautelosa do liderado no que tange a busca pelo conhecimento, em detrimento de ações por 
parte dos líderes. Ficou demonstrado que há uma iniciativa perceptível dos colaboradores em buscar por si mesmos, de modo constante, por cursos e capacitações que contribuam e aprofundem os conhecimentos em sua área de especialidade. Investe-se especialmente em cursos que desenvolvam habilidades com o intuito de aprofundar estrategicamente os conhecimentos em determinada área (Borges, 2017), demonstrando uma tendência a um comportamento proativo dos colaboradores.

No que tange à dimensão de competência denominada habilidade, observou-se predominância da habilidade de saber trabalhar em equipe como fundamental para a competência de um profissional em contextos ágeis de gerenciamento de projetos. Isso se deve ao fato, principalmente, da forma como os times se estruturam, que são por meio dos squads, uma vez que os resultados positivos são potencializados pelo compartilhamento de conhecimento e colaboração, tornando todos os membros responsáveis pelo melhor resultado dos projetos. Ressalta-se, portanto, que o trabalho em equipe só se torna efetivo, producente e construtivo se desenvolvidas outras habilidades, tais como comunicação, flexibilidade, liderança e capacidade de execução.

Quanto à atitude dos colaboradores, observou-se que o aspecto proatividade é aquele que mais confere competência ao time de trabalho em contextos ágeis de gerenciamento de projetos, contribuindo para o compartilhamento de boas soluções para o projeto, seu desempenho pessoal e assim para os resultados. Gava (2009) corrobora esse aspecto ao declarar que o comportamento proativo influencia positivamente a performance empresarial, tendo como consequência resultados superiores àqueles comportamentos que somente respondem relativamente ao mercado.

Em suma, essa pesquisa possibilitou identificar as principais competências valorizadas no time que utiliza abordagem ágil de gerenciamento de projetos, que são conhecimento técnico especializado, conhecimento de métodos ágeis de projetos, comunicação, saber trabalhar em equipe, capacidade de execução, flexibilidade, liderança, colaboração e proatividade. Observou-se, ainda, que as competências abordadas no estudo estão em consonância às competências demandas aos profissionais do futuro de acordo com o relatório do Fórum Econômico Mundial. Desta forma, constatouse que o time pesquisado está no caminho de ser uma equipe de alta performance, mesmo que ainda seja necessário que os membros incorporem mais as práticas ágeis, entendendo o real valor que geram para os clientes por meio do desenvolvimento dos seus produtos.

Considera-se que o estudo obteve resultados positivos ao atender a proposta do objetivo de pesquisa, mesmo com as limitações existentes em um estudo de caso único, o qual representa somente uma realidade específica. Para estudos futuros, sugere-se realizar essa 
entrevista em outras empresas que utilizam abordagem ágil, seguindo o mesmo roteiro semiestruturado, além de realizar um acompanhamento sistemático e longitudinal das atividades diárias do grupo estudado, possibilitando uma melhor percepção do meio e resultados mais robustos da pesquisa.

Compreende-se que a identificação e gestão de competências dos colaboradores poderá auxiliar gestores a construir equipes de alta performance para obter melhores resultados para a organização, o que revela a importância e a relevância desse campo de pesquisa, uma vez que as organizações buscam resultados cada vez mais efetivos e desempenho mais elevado de sua equipe.

\section{Referências}

Almeida, C. C., Campagnac, L. A., \& Farias Filho, J. R. (2008). Em busca do perfil ideal de gerente para alcançar o sucesso dos projetos. Congresso Nacional de Excelência em Gestão, Niterói, RJ, Brasil, 4.

Amaral, D. C., Conforto, E. C., Benassi, J. L. G., \& Araújo, C. (2011).Gerenciamento ágil de projetos: aplicação em produtos inovadores. São Paulo: Saraiva.

Balle, A. R. (2011). Análise de metodologias ágeis: conceitos, aplicações e relatos sobre XP e Scrum. Monografia de graduação, Instituto de Informática, Universidade Federal do Rio Grande do Sul Porto Alegre, RS, Brasil.

Barato, J. N. (1998). Competências essenciais e avaliação do ensino universitário.

Brasília: Ed. da UnB.

Bardin, L. (2011). Análise de conteúdo. São Paulo: Edições 70.

Betti, S. (2011). Formando equipes de alta performance. Recuperado em 14 abril, 2018, de https://endeavor.org.br/equipes-de-altaperformance-como-chegar-la/.
Boerg, J. (2018). Kanban em 10 passos. InfoQ Brasil. Recuperado em 10 novembro, 2018, de http://www.gianfratti.com/WP/wpcontent/uploads/2018/04/InfoQBrasilKanban10Passos. pdf.

Borges, A. (2017, maio). Especialização profissional: entenda a importância da sua carreira. Recuperado em 01 novembro, 2018, de

http://igceducacao.com.br/postagemblog/especializacao-profissional-entendaimportancia-para-sua-carreira/.

Bryman, A. (1989). Research methods and organization studies.London: Unwin Hyman.

Camara, I. (2018). Edtech: revolução na área educacional.Recuperado em10 novembro, 2018, de https://www.startse.com.

Carvalho, B. V., \& Mello, C. H. P. (2009). Revisão, análise e classificação da literatura sobre o método de desenvolvimento de produtos ágil Scrum. Anais do Simpósio de Administração da Produção, Logística e Operações Internacionais, São Paulo, SP, Brasil, 12.

Carvalho, M., \& Laurindo, F. (2003). Estratégia para competitividade (1a ed.). São Paulo: Futura.

Chiavenato, I. (2004). Gestão de pessoas. Rio de Janeiro: Elsevier.

Cruz, F. (2013). Scrum e PMBOK unidos no gerenciamento de projetos. Rio de Janeiro: Brasport.

Cruz, F. (2014, dezembro). A comunicação da escuta. Recuperado em 29 outubro, 2018 de http://www.fabiocruz.com.br/comunicacaoescuta/.

Durand, T. (1998). Forms of incompetence. Proceedings of the International Conference on Competence-Based Management, Oslo, EUA, 4.

Dyer, W. G., \& Dyer, J. H. (2011). Equipes que fazem a diferença (Team Building): estratégias comprovadas para desenvolver equipes de alta performance. São Paulo: Saraiva.

Gava, R. (2009). Proatividade de mercado: construção de um modelo teórico. Tese de doutorado, Programa de Pós-Graduação em Administração da Universidade Federal do Rio Grande do Sul, Porto Alegre, RS, Brasil. 
Godoy, A. S. (1995). Pesquisa qualitativa: tipos fundamentais. Revista de Administração de Empresas, 35(3), 20- 29. https://doi.org/10.1590/S003475901995000300004. Recuperado em 14 abril, 2018 de https://www.scielo.br/pdf/rae/v35n3/a04v35 n3.pdf.

Harvard Business School (1997). Project management manual. Boston: HBS.

Highsmith, J. et al.(2001). Manifesto for agiledevelopment. USA. Recuperado em14 abril, 2018 de http://agilemanifesto.org/.

Juran, J. M., \& Godfrey, A. B. (1998). Juran' quality handbook (5a ed.). New York: McGraw-Hill.

Le Boterf, G. (1995). De la compétence: essai sur un attracteur étrange.Paris: LesÉditions d'Organisations.

Leme, R. (2005). Aplicação prática de gestão de pessoas por competências. Rio de Janeiro: Qualitymark.

Lima, N. C. (2012). Aplicação da gestão ágil no gerenciamento de projetos. Linguagem Acadêmica, 2(1), 201-223. Recuperado em 18 novembro, 2018 , de https://intranet.redeclaretiano.edu.br/downlo ad?caminho=upload $/ \mathrm{cms} /$ revista/sumarios $/ 8$ 3.pdf\&arquivo $=$ sumario11.pdf.

López-Bao, J. V., Palomares, F., Rodríguez, A., \&Ferreras, P. (2011). Intraspecific interference influences the use of prey hotspots. Oikos, 120(10), 1489-1496. https://doi.org/10.1111/j.16000706.2011.19194.x.

Magill, R. A. (2000). Aprendizagem motora: conceitos e aplicações. São Paulo: Edgard Blücher.

Mariano, A. D. (2008). Gerenciamento de portfólio de projetos: fatores críticos de sucesso e impactos sobre os resultados organizacionais.Dissertação de mestrado, Programa de Pós-Graduação em Administração, Faculdade de Economia, Administração e Contabilidade, Universidade de São Paulo, São Paulo, SP, Brasil.

Marques, J. R. (2016, abril). O que é adaptabilidade. Goiânia: Instituto Brasileiro de Coaching. Recuperado em 01 novembro, 2018, de http://www.ibccoaching.com.br/portal/oque-e-adaptabilidade/.
Martin, S. B. (1997). Redes sociais e flexibilidade do trabalho: uma análise comparativa. Revista Latinoamericana de Estudios del Trabajo, 3(6), 9-38.

Miguel, P. A. C. (2007). Estudo de caso na engenharia de produção: estruturação e recomendações para sua condução. Produção, 17(1), 216-229. https://doi.org/10.1590/S010365132007000100015. Recuperado em 06 julho, 2018, de https://www.scielo.br/pdf/prod/v17n1/14.pd f.

Motta, P. R. M. (2004). Gestão contemporânea: a ciência e a arte de ser dirigente. Rio de Janeiro: Record.

Nonaka, I., \&Takeuchi, H. (1997). Criação do conhecimento na empresa. Rio de Janeiro: Campus.

Olabuenaga, J. I. R., \&Ispizua, M.A. (1989). La descodificacion de la vida cotidiana: metodos de investigacioncualitativa. Bilbao: Universidad de Deusto.

Paradela, T., \&Peeters, S. (2001).Trabalhar ou ficar em casa?: perspectivas do trabalho remoto.Anais do Encontro Nacional de Engenharia de Produção, Salvador, BA, Brasil, 21.Recuperado em 06 julho, 2018, de http://www.abepro.org.br/biblioteca/ENEG EP2001_TR41_0374.pdf

Parry, S. B. (1996).The quest for competences. Training, 33(7), 48-56.

Pati, C. (2016, Janeiro 22). 10 competências que todo profissional vai precisar até 2020 . Exame.Recuperado em 14 abril, 2018 de https://exame.abril.com.br/carreira/10competencias-que-todo-professional-vaiprecisar-ate-2020/.

Prado, D. (2009). Gerenciamento de portfólios, programas e projetos nas organizações. Nova Lima: INDG Tecnologia e Serviços.

Prahalad, C. K., \&Hamel, G. (1990). The core competence of the corporation. Harvard Business Review, 3,79-91. Recuperadoem 06 julho, 2018, de http://www.personal.psu.edu/ kkm11/files/HandP_Core\%20Competence\% 20of\%20the\%20organization.pdf.

Prikladnicki, R., Willi, R., \&Milani, F. (2014). Métodos ágeis para o desenvolvimento de software. Porto Alegre: Bookman.

Project Management Institute (2017). A guide to the Project Management Body of 
Knowledge: PMBOK® Guide (6a ed.). Pennsylvania: PMI.

Rabaglio, M. O. (2001). Seleção por competências (2a ed.). São Paulo: Educator.

Rebelo, Paulo. (2013, fevereiro 26). Escalando o Agile na Spotify: exemplo de sucesso de Lean Startup, Scrum e Kanban.InfoQ, Recuperado em 18 novembro, 2018, de https://www.infoq.com/br/articles/spotifyescalando-agile.

Robbins, S. P. (2005). Comportamento organizacional.São Paulo: Pearson Prentice Hall.

Rotta, M., Rados, G. J. V., Trierweiller, A. C., \& Silva, S. M. (2015). Implantação de métodos ágeis em empresa de desenvolvimento de software: um estudo de caso. Congresso do Conhecimento e Inovação,Joiville, SC, Brasil, 5.

Sabbagh, R. (2013). Scrum: gestão ágil para projetos de sucesso. São Paulo: Casa do código.

Schwaber, K. (2014). Agileproject management withScrum. Cranbury, $\mathrm{NJ}$ : Microsoft Press.

Sefiani, N., Boumane, A., Campagne, J. P., \&Bouami, D. (2012). Process of identifying competencies based on a functional approach. International Journal of EngineeringScience and Technology, 4(1), 265-275.

Sutherland, J., \&Schwaber, K. (2013). Um guia definitivo para o Scrum: as regras do jogo. Guia do Scrum. Recuperado em 11 novembro, 2018, de https://www.scrumguides.org/docs/scrumgui de/v1/Scrum-Guide-Portuguese-BR.pdf.

Terry, R. G. (1960). Pensamentos de Terry. Pensador. Recuperado em 10 outubro, 2018, de

https://www.pensador.com/frase/NTc5ODg $2 /$.

Yukl, G. (2013). Leadership in organizations (8a. ed.). Engle-wood Cliffs, NJ: Prentice Hall. 